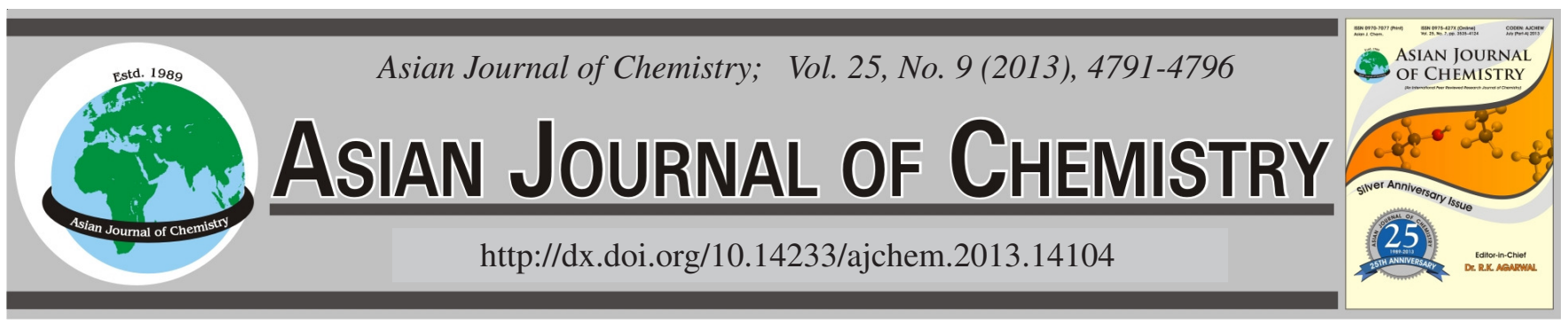

\title{
Structural Investigation of $\mathrm{Cu}(\mathrm{II})$ in Alkaline Salt of Bis(malonato)zincate(II) Anion Using Single Crystal EPR Technique
}

\author{
P. GeEtha ${ }^{1, *}$, K. PARThipan ${ }^{2,3}$, P. Sathya ${ }^{2}$ and S. Balaji ${ }^{1}$
}

1Sri Chandrasekharendra Saraswati Viswa Mahavidyalaya, Kanchipuram-631 561, India
${ }^{2}$ Department of Chemistry, Pondicherry University, Puducherry-605 014, India
${ }^{3}$ AM Jain College, Meenampakkam, Chennai-600 114, India
*Corresponding author: E-mail: prabhakaran.geetha@yahoo.com; kanchiuniv.chem@gmail.com

\begin{abstract}
Electron paramagnetic resonance and optical absorption spectra of $\mathrm{Cu}(\mathrm{II})$ ion doped diaquacesiumaquabismalonatozincate have been carried out at room temperature using $\mathrm{X}$ band spectrometer to get information about the location of impurity and assigned structural properties. Single crystal rotated along the three crystal planes $\left(a^{*} c^{*}, b^{*}, a b\right)$ suggesting the presence of single site copper impurity present in the lattice. The observed spectra have been fitted to spin Hamiltonian of rhombic symmetry with $g_{x x}=2.1694, g_{y y}=2.137, g_{z z}$ $=2.3304 ; \mathrm{A}_{\mathrm{xx}}=3.75, \mathrm{~A}_{\mathrm{yy}}=6.79$ and $\mathrm{A}_{\mathrm{zz}}=12.76 \mathrm{mT}$, respectively. From the direction cosines of principal $\mathrm{g}$ and $\mathrm{A}$ values propose that the copper present in the lattice interstitially in the host lattice. The analysis of powder spectrum also confirms the presence of only one site. Angular variation plots and power EPR spectrum have also been simulated. Optical, FTIR and powder XRD techniques have been used to confirm the structure of the host lattice in presence of dopant.
\end{abstract}

Key Words: EPR, Hyperfine, Spin hamiltonian, Crystal lattice, Admixture coefficient, Interstitial.

\section{INTRODUCTION}

Coordination polymers of malonic acid displayed attractive properties such as metal organic frame work, supramolecular behaviours, biological properties, molecular electronics, catalysis and molecular based magnetic materials etc. Additionally malonic acid with diethyl ester is used for the manufacturing of vitamins B1 and B6, barbiturates and numerous other valuable compounds. And it is an important compound, used in various field of science especially biological and medical fields. For example, malonate is a powerful competitive inhibitor for cellular respiration, because it binds with the active site of succinate dehydrogenase in the citric acid cycle ${ }^{1,2}$. The malonate dianion acts as a bi- or tridentate bridging ligand to form various structural topologies and also behaves as flexible and as well as versatile. Zinc complexes of malonic acid have number of dentateing abilities. These ligands form complexes with of bridging types also. An essential important quality of the malonic acid bridge is that the magnitude of the exchange interaction mainly depends on the possible bridging modes. Because the malonate complexes exhibits ferro- or antiferromagnetic interactions, which are controlled by the dimensionality of the structure. Moreover, the carboxylate group affords an efficient pathway for the magnetic centres to couple the magnetic centers either ferro- or antiferromagnetically ${ }^{3-9}$.
Copper is one of the most copious transition metal present in naturally occurring systems. $\mathrm{Cu}$ (II) ion is interesting because of its $3 d^{9}$ electronic configurations with one unpaired electron. EPR of $\mathrm{Cu}(\mathrm{II})$ has been probe in a wide range of symmetry environments, viz., octahedral, tetrahedral, square planar, square pyramidal and trigonal bipyramidal ${ }^{10-17}$. Single crystal EPR studies also exposed the location of paramagnetic impurity, i.e., interstitial, substitutional or both. As our literature knowledge there is no report on the single crystal EPR studies of copper doped in diaquacesiumaquabismalonatozincate, the present investigation focus on EPR and optical studies of copper doped in diaquacesiumaquabismalonatozincate polymer (here after abbreviated as DCBMZ) has been undertaken to find the spin Hamiltonian parameters, the location of dopant, structural and bonding parameters.

\section{EXPERIMENTAL}

Single crystals of copper doped DCBMZ was prepared by literature procedure ${ }^{18}$. Solid zinc carbonate has been added to an aqueous solution of malonic acid, which is kept under stirring. These solutions were stirred for $0.5 \mathrm{~h}$ and followed by refluxing on water bath. At this stage, $0.1 \%$ by weight of copper sulphate was added as dopant. An aqueous solution $(10 \mathrm{~mL})$ of cesium carbonate $(0.116 \mathrm{~g}, 1 \mathrm{mmol})$ is added gradually to the above reaction mixture with continuous stirring 
and refluxing. After half an hour, the reaction mixture was cooled down to the room temperature ${ }^{18}$. The resulting solution was allowed to stand at room temperature. After couple of weeks, as a result, good and well shaped crystals were separated out from the solution.

EPR studies: The EPR spectra were recorded at room temperature on a JEOL JES-TE100 ESR spectrometer operating at X-band frequencies, having a $100 \mathrm{kHz}$ field modulation to obtain the first derivative EPR spectrum. DPPH was used as the standard for magnetic field correction and for $\mathrm{g}$-factor calculations. Angular variation was made at room temperature by rotating the crystal along the three mutually orthogonal axes $\mathrm{a}, \mathrm{b}, \mathrm{c}^{*}$ in at $10^{\circ}$ intervals. Isofrequency plots of each plane were simulated using EPR-NMR program. The EPR spectrum of for the powder sample was simulated using Simfonia program developed and supported by Bruker Biospin.

Optical absorption: Optical spectrum of copper doped DCBMZ was recorded at room temperature using a Varian Cary 5000 Ultraviolet (UV-visible) near infrared spectrophotometer in the region of 200-1200 nm.

FTIR and powder XRD studies: FTIR spectrum of copper doped DCBMZ was recorded at room temperature. In the our present study, the FTIR spectra was recorded on a Shimadzu FTIR -8300/8700 spectrometer, $4 \mathrm{~cm}^{-1}$ resolution, automatic gain, $20 \mathrm{scan}$, in the region of $4000-400 \mathrm{~cm}^{-1}$. The measurements were made using almost transparent $\mathrm{KBr}$ pellets containing fine powder sample at room temperature. In the crystalline material, the powder X-ray diffraction pattern (XRD) was used to identify and characterize confirms the powder sample possessing a long and short range order, respectively. In the present investigation, the powder XRD were carried out for with doped and undoped materials on a PANalytical Xpert Pro diffactometer with $\mathrm{CuK}_{\alpha}$ radiation of wavelength $0.15406 \mathrm{~nm}$ and $2 \theta$ values of $5-75^{\circ}$.

Crystal structure: Diaquacesiumaquabismalonatozincate (DCBMZ) with molecular formula $\mathrm{C}_{6} \mathrm{H}_{12} \mathrm{Cs}_{2} \mathrm{ZnO}_{12}$. DCBMZ is isostructural with $\mathrm{C}_{6} \mathrm{H}_{12} \mathrm{Cs}_{2} \mathrm{CuO}_{12}$ and belongs to a triclinic crystal class with space group $\mathrm{PI}^{-}$, having unit cell parameters $\mathrm{a}=0.71166, \mathrm{~b}=0.71316, \mathrm{c}=0.75211 \mathrm{~nm}$ and $\alpha=87.33^{\circ}, \beta=$ $79.42^{\circ}, \gamma=86.69^{\circ}$ and $\mathrm{Z}=1^{18}$. The structure of DCBMZ have made up $\left[\mathrm{Zn}(\mathrm{mal})_{2}\left(\mathrm{H}_{2} \mathrm{O}\right)_{2}\right]^{2-}$ anion and $\left[\mathrm{Cs}\left(\mathrm{H}_{2} \mathrm{O}\right)\right]^{+}$cations which liked by hydrogen bond leading thus to 3D network. Two complexes having two metal atoms namely zinc and cesium. Zinc atom is coordinate with six oxygen atom, four carboxylate oxygen atoms from two different malonate carboxyl groups and two oxygen from water molecule as exhibiting an elongated octahedral geometry. The cesium atom is eight coordinated exhibiting a highly distorted square antiprism environment. Two water molecules and two carboxylate malonate oxygen atoms build one basal plane of the square antiprism. The other basal plane of the squre antiprism, which is four carboxylate oxygen atoms from three different malonate groups, is slightly distorted. The structure of the DCBMZ is shown in Fig. 1.

Optical absorption, FTIR and powder XRD studies of Cu(II) doped DCBMZ: The optical adsorption spectrum is recorded at room temperature and shown in Fig. 2a. The optical absorption studies of copper doped DCBMZ shows two bands

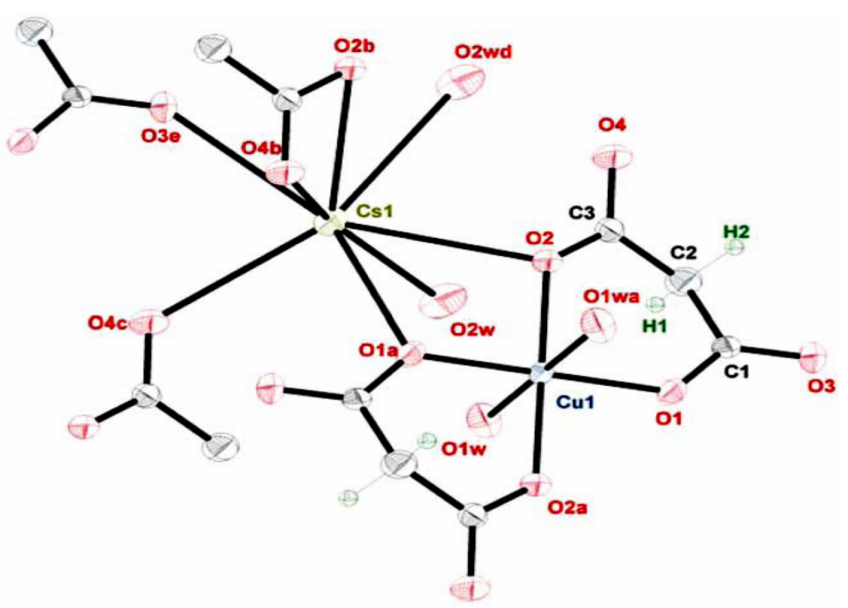

Fig. 1. Molecular packing diagram for $\mathrm{DCBMZ}^{18}$

at 42735 and $15649 \mathrm{~cm}^{-1}$. The strong band has been observed at in the range of $42735 \mathrm{~cm}^{-1}$ and which is assigned as charge transfer band, which usually occurred in the range of 50000$35000 \mathrm{~cm}^{-1}$. Another broad band at $15649 \mathrm{~cm}^{-1}$ is an attribute of the copper ion in tetragonal distorted octahedral symmetry. According to this, the broad band is assigned to transition between ${ }^{2} \mathrm{~B}_{1 \mathrm{~g}}{ }^{2} \mathrm{~B}_{2 \mathrm{~g}}$. Using the above mention transition, we have calculate tetragonal distortion parameter $(\mathrm{Dq}) 10 \mathrm{Dq}=15649$ $\mathrm{cm}^{-1} 19$.

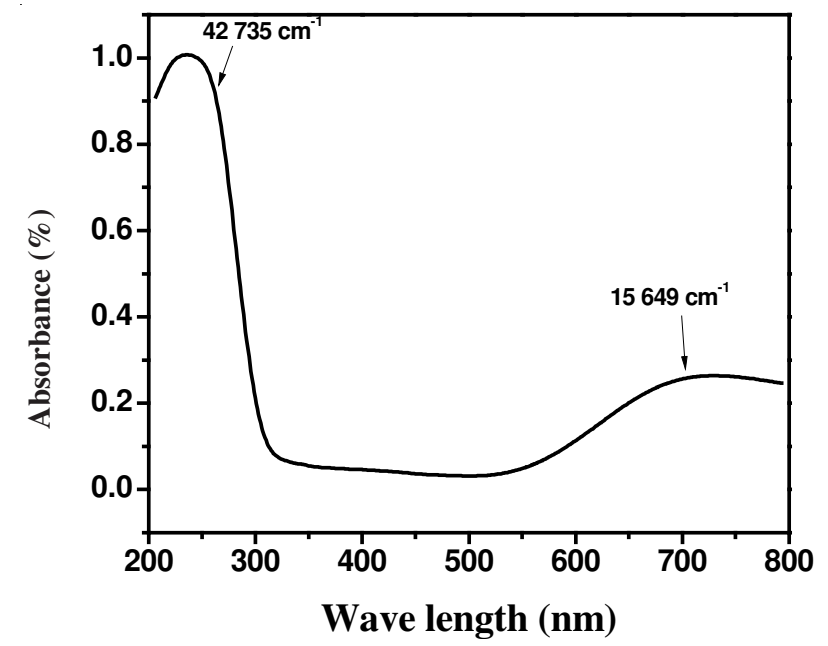

Fig. 2. (a) Powder optical absorption spectrum of $\mathrm{Cu}$ (II) doped DCBMZ at room temperature

The FTIR spectrum of $\mathrm{Cu}(\mathrm{II})$ doped DCBMZ is recorded at room temperature is shown in Fig. 2b. The band observed at $1655 \mathrm{~cm}^{-1}$ is appropriated to carboxylate $\left(\mathrm{COO}^{-}\right)$symmetrical stretching and the bands observed around at 3436 and 3105 $\mathrm{cm}^{-1}$ are allocated to $\mathrm{O}-\mathrm{H}$ bending corresponding to water ligand. Three bands are noticed at 975,788 and $732 \mathrm{~cm}^{-1}$ corresponds to bending modes of $\mathrm{O}-\mathrm{C}-\mathrm{O}$ bond. The band is observed at $1445 \mathrm{~cm}^{-1}$ corresponds to $\mathrm{C}=\mathrm{C}$ stretching. However, this spectrum is supportive to confirm that there is no structural changes has been takes place after doping DCBMZ with small amount of $\mathrm{Cu}(\mathrm{II})$ impurity.

The powder XRD pattern of $\mathrm{Cu}(\mathrm{II})$ doped DCBMZ and pure DCBMZ were recorded at room temperature is shown in Fig. 2c. Crystal lattice parameters a, b, c for both copper doped 


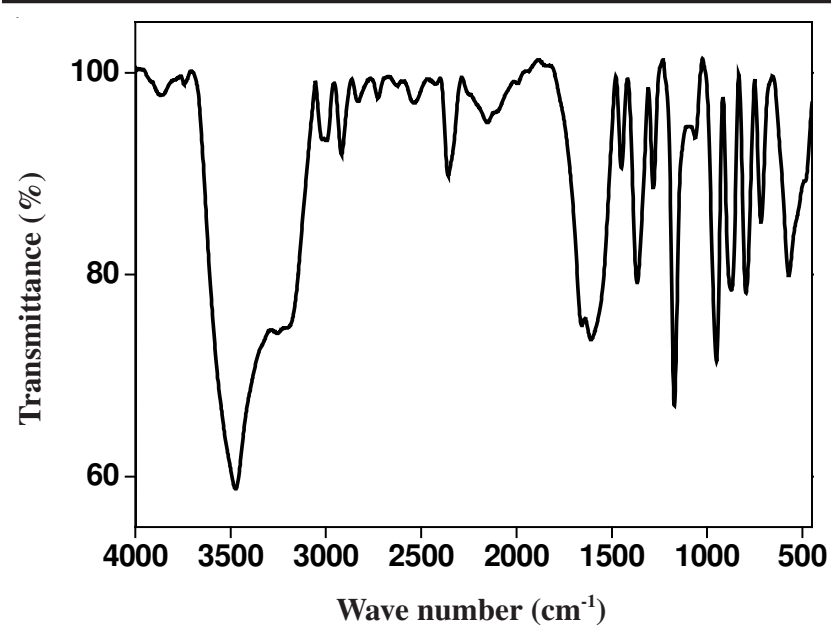

Fig. 2. (b) FTIR spectrum of $\mathrm{Cu}(\mathrm{II})$ doped DCBMZ $\mathrm{D}_{\mathrm{q}}=1564 \mathrm{~cm}^{-1}$

DCBMZ and pure DCBMZ have been calculated from powder $X R D$. These values are same resembles with the reported DCBMZ and it confirms that the formation of lattice DCBMZ. Low concentration of copper impurity does not alter structure.

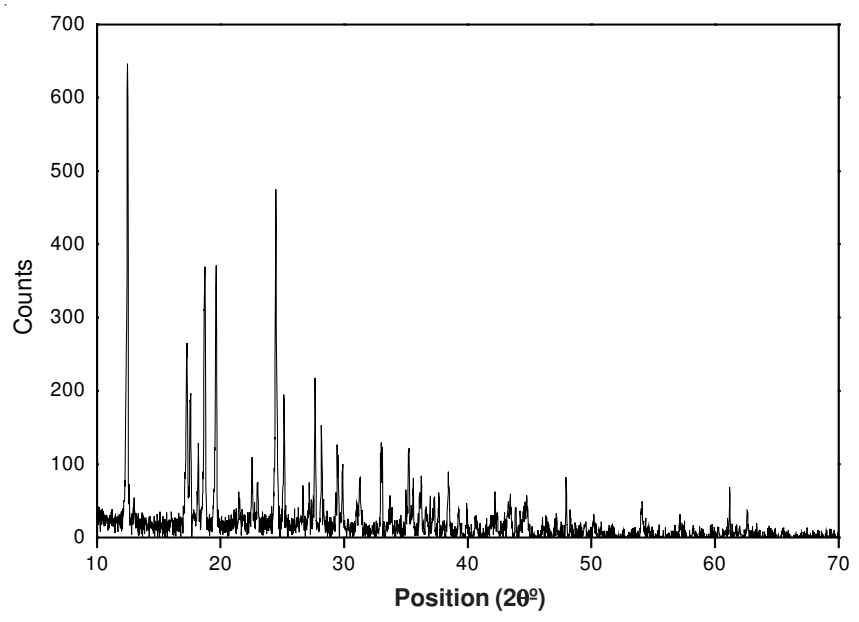

Fig. 2. (c) Powder XRD pattern of $\mathrm{Cu}(\mathrm{II})$ doped DCBMZ

EPR studies: Light blue colour copper doped diaquacesiumaquabismalonatozincate single crystal is obtained by slow evaporation method. Good and proper size crystal have selected and fixed into the EPR cavity by rotating the crystal in three mutually orthogonal planes namely a*c*, bc*, $a * b$ for every 10 degree interval. Here axis $c^{*}$ is perpendicular to the crystal axis $b$ in the plane and axis $a *$ is orthogonal to the axes $b$ and $c^{*}$. Initially, the crystal rotations are performed at RT to assess the type of JT effect, if any. It is generally known that if the EPR lines are invariant for single crystal rotations at RT, it is called dynamic JT or tunneling. In contrast, if the copper hyperfine lines are not resolved, but illustrate angular dependence it corresponds to static JT. For the present system behaves as anisotropic and with well resolved hyperfine lines at room temperature, it says absence of JT. The observed single crystal EPR spectrum of $\mathrm{Cu}(\mathrm{II})$ doped DCBMZ in $\mathrm{a}^{*} \mathrm{c}$ * plane are displayed in Fig. 3a, when the crystal $\mathrm{c} *$ axis is parallel to applied magnetic field. Single crystal EPR measurements of $\mathrm{Cu}$ (II) doped DCBMZ show well separated four line hyperfine lines have been occurred due to the coupling of electron $\mathrm{S}=1 / 2$ (electron spin) of copper, with its nuclear spin $\mathrm{I}=3 / 2$ (for both ${ }^{63} \mathrm{Cu}$ and ${ }^{65} \mathrm{Cu}$ naturally abundant isotopes) and its clearly says only one site present in the lattice. Because the unit cell have one molecule $(Z=1)$ there is no way to entered another site this same phenomenon have been monitored for vanadyl doped DCBMZ. Two more EPR spectra in of $a b$ and $b c^{*}$ planes are given in Fig. $3 b$ and c, respectively with their indicated orientations.

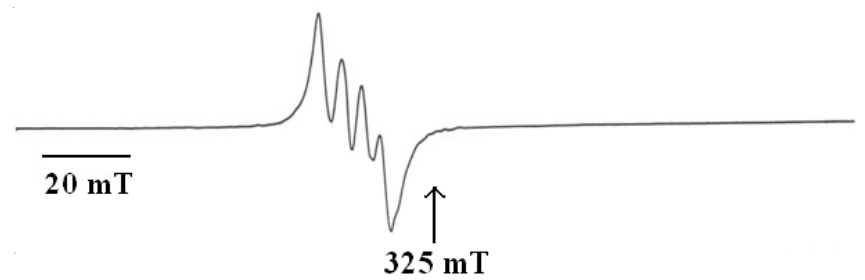

Fig. 3. (a) Single crystal EPR spectrum of $\mathrm{Cu}$ (II) doped DCBMZ recorded, when A parallel to axis c. Frequency $=9.06849 \mathrm{GHz}$

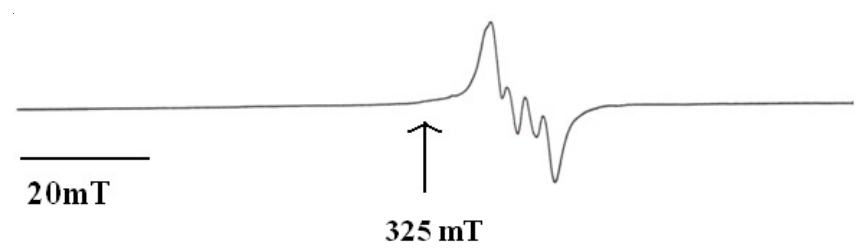

Fig. 3. (b) Single crystal EPR spectrum of $\mathrm{Cu}(\mathrm{II})$ doped DCBMZ, when B is parallel to the axis $\mathrm{c}^{*}$. Frequency $=9.06856 \mathrm{GHz}$

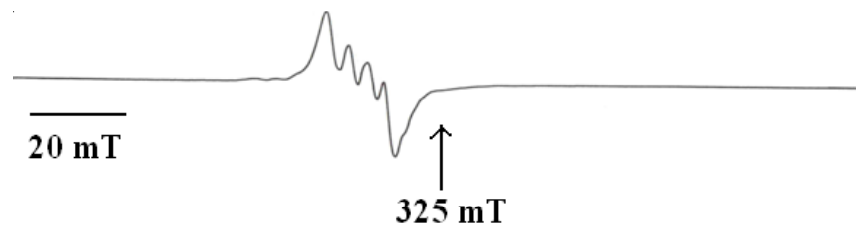

Fig. 3. (c) Single crystal EPR spectrum of $\mathrm{Cu}$ (II) doped DCBMZ, when applied magnetic field $(B)$ is parallel to axis a. Frequency $=9.07554$ $\mathrm{GHz}$

During crystal rotations in all the three planes, a maximum four lines have been visualized. Angular variation plots of hyperfine lines in the three planes ac*, bc* and ab, respectively are shown in Fig. 4a. In these figures, solid circle represents the experimental point values whereas the continuous straight line represents simulated points. A good concurrence has been established. In Fig. 4b and c, solid circles indicate experimental points, whereas the solid lines correspond to theoretical line positions, obtained using EPR-NMR program and data given in Table-1. $v=9.06849 \mathrm{GHz}$.

Calculation of spin-Hamiltonian $(\mathrm{Hs})$ parameters: The EPR spectrum of $\mathrm{Cu}(\mathrm{II})$ ion $(\mathrm{S}=1 / 2, \mathrm{I}=3 / 2)$ might be fitted to the following spin Hamiltonian parameters ${ }^{20}$

$\mathrm{Hs}=\mathrm{g}_{\mathrm{xx}} \beta \mathrm{B}_{\mathrm{x}} \mathrm{S}_{\mathrm{x}}+\mathrm{g}_{\mathrm{yy}} \beta \mathrm{B}_{\mathrm{y}} \mathrm{S}_{\mathrm{y}}+\mathrm{g}_{\mathrm{zz}} \beta \mathrm{B}_{\mathrm{z}} \mathrm{S}_{\mathrm{z}}+\mathrm{A}_{\mathrm{xx}} \mathrm{S}_{\mathrm{x}} \mathrm{I}_{\mathrm{x}}+\mathrm{A}_{\mathrm{yy}} \mathrm{S}_{\mathrm{y}} \mathrm{I}_{\mathrm{y}}+\mathrm{A}_{\mathrm{zz}} \mathrm{S}_{\mathrm{z}} \mathrm{I}_{\mathrm{z}}$

This includes only electron Zeeman and hyperfine interactions. The quadrupole and nuclear Zeeman interactions have been neglected. The spin orbit interaction is an intrinsic in $g$ and A tensor, which is constructed and diagnosed to find the principle values. By making use of the EPR-NMR ${ }^{20}$ program, the various spin Hamiltonian parameters $g$ and $\mathrm{A}$ has been calculated using the isofrequency plots and their values are given in Table- 1 along with their respective direction cosines. 


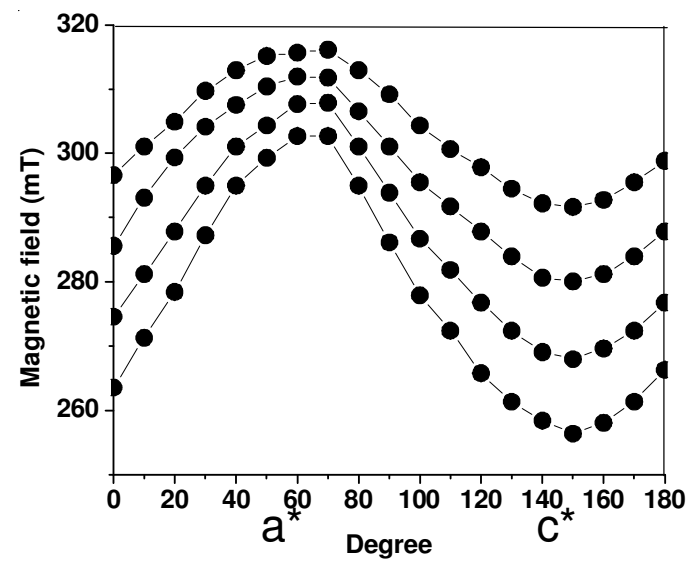

Fig. 4. (a) Angular variation plots of $\mathrm{Cu}(\mathrm{II}) / \mathrm{DCBMZ}$ in $\mathrm{a}^{*} \mathrm{c}^{*}$ plane at room temperature. Here $\theta=140^{\circ}$ corresponds to the $\mathrm{c}^{*}$ axis and $\theta=50^{\circ}$ corresponds to the crystallographic axis

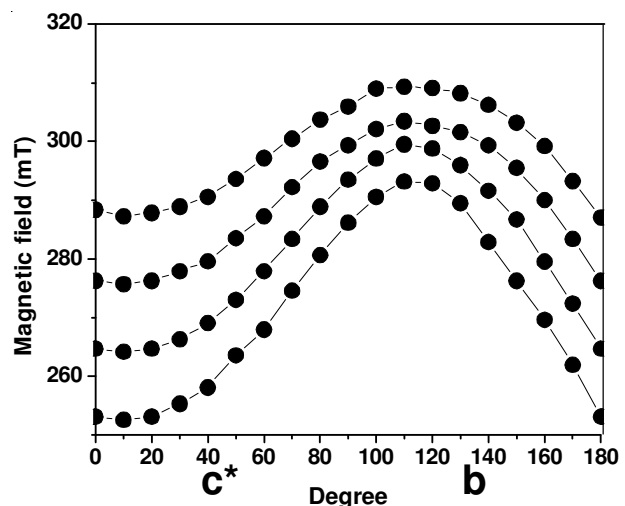

Fig. 4. (b) Angular variation plots of $\mathrm{Cu}(\mathrm{II}) / \mathrm{DCBMZ}$ in bc* plane at room temperature. Here $\theta=40^{\circ}$ corresponds to the $c^{*}$ axis and $\theta=50^{\circ}$ corresponds to the crystallographic $b$ axis. $\theta=9.06856 \mathrm{GHz}$

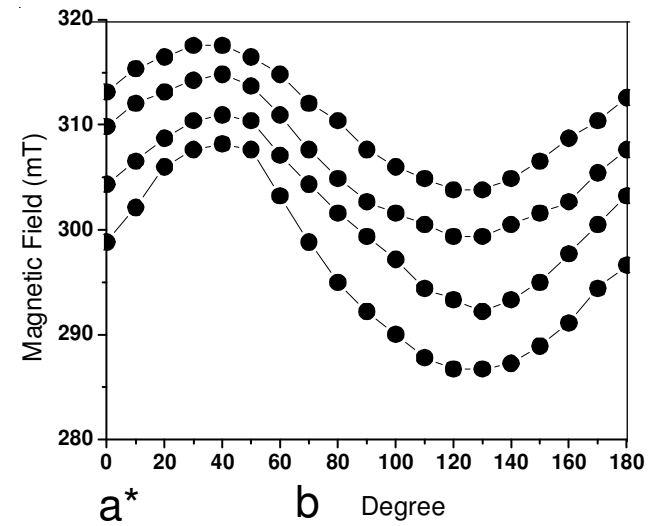

Fig. 4. (c) Angular variation plots of $\mathrm{Cu}(\mathrm{II}) / \mathrm{DCBMZ}$ in ab plane at room temperature. Here $\theta=0^{\circ}$ corresponds to the $\mathrm{a}^{*}$ axis and $\theta=80^{\circ}$ corresponds to the crystallographic $b$ axis. $v=9.07554 \mathrm{GHz}$

The spin Hamiltonian parameters for few related host lattices are tabulated listed in Table-3 along with $\mathrm{Cu}$ (II) doped DCBMZ. The spin Hamiltonian parameters obtained in the present case are characteristic of $\mathrm{Cu}$ (II) ion in the orthorhombic symmetry. Another fascinating parameter is called as $\mathrm{R}$ it is helpful to find the position unpaired electron $t_{2 g}$ or $\mathrm{e}_{\mathrm{g}}$. The $\mathrm{R}$ factor given by $R=\left(g_{x}-g_{y}\right) /\left(g_{z}-g_{x}\right)$ (where $\left.g_{z}>g_{x}>g_{y}\right)$. The $R$ value is greater than unity, ground state is predominantly $\mathrm{d}_{\mathrm{z}}^{2}$ and, if it is less than unity, it means that the unpaired electron is predominantly present in the $\mathrm{dx}^{2}-\mathrm{y}^{2}$ state. In the calculated
TABLE-1

SPIN HAMILTONIAN PARAMETERS OBTAINED FROM THE SINGLE CRYSTAL ROTATIONS FOR $\mathrm{Cu}$ (II) IN DCBMZ USING PROGRAM EPR-NMR ${ }^{20}$

Principle values Direction cosines

\begin{tabular}{|c|c|c|c|c|c|c|}
\hline \multicolumn{4}{|c|}{ Fincipie values } & \multicolumn{3}{|c|}{ 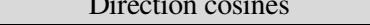 } \\
\hline \multicolumn{4}{|c|}{ g matrix } & $\mathrm{a}$ & b & $\mathrm{c}^{*}$ \\
\hline \multirow{3}{*}{2.192} & -0.06 & -0.57 & 2.169 & 0.7935 & 0.2391 & 0.5594 \\
\hline & 2.242 & 0.040 & 2.137 & -0.2661 & -0.6904 & 0.6726 \\
\hline & - & 2.197 & 2.330 & -0.5471 & 0.6887 & 0.4829 \\
\hline \multicolumn{4}{|c|}{ A matrix (mT) } & $\mathrm{a}$ & $\mathrm{b}$ & $\mathrm{c}^{*}$ \\
\hline \multirow{3}{*}{7.38} & -4.25 & -1.45 & 6.79 & 0.7489 & 0.6590 & 0.0694 \\
\hline & 8.21 & 1.23 & 3.50 & 0.1742 & -0.2968 & 0.9388 \\
\hline & - & 7.45 & 12.76 & -0.6393 & 0.6910 & 0.3371 \\
\hline
\end{tabular}

TABLE-2

DIRECTION COSINES OF Zn-O BONDS IN DCBMZ OBTAINED FROM THE CRYSTALLOGRAPHIC DATA ${ }^{18}$

\begin{tabular}{cccc}
\hline \multirow{2}{*}{ M-L bond } & \multicolumn{3}{c}{ Direction cosines } \\
\cline { 2 - 4 } & $\mathrm{a}^{*}$ & $\mathrm{~b}^{*}$ & $\mathrm{c}^{*}$ \\
\hline $\mathrm{Zn}-\mathrm{O} 1 \mathrm{~m}$ & 0.1438 & -0.8278 & 0.4894 \\
$\mathrm{Zn}-\mathrm{O} 2 \mathrm{~m}$ & 0.1653 & 0.4314 & 0.8874 \\
$\mathrm{Zn}_{\mathrm{n}} \mathrm{O}_{\mathrm{w}}$ & 0.9051 & 0.4195 & 0.0688 \\
\hline
\end{tabular}

\begin{tabular}{|c|c|c|c|c|c|c|c|}
\hline \multicolumn{8}{|c|}{$\begin{array}{c}\text { TABLE-3 } \\
\text { SPIN HAMILTONIAN PARAMETERS FOR Cu(II) IN } \\
\text { DCBMZ AND FEW RELATED HOST LATTICES } \\
\end{array}$} \\
\hline \multirow[t]{2}{*}{ Lattices } & \multicolumn{3}{|c|}{ Spectroscopic splitting } & \multicolumn{3}{|c|}{$\begin{array}{c}\text { Hyper fine constant } \\
\text { A (mT) }\end{array}$} & \multirow[t]{2}{*}{ Ref. } \\
\hline & $\mathrm{g}_{z z}$ & $g_{x x}$ & $\mathrm{~g}_{\mathrm{yy}}$ & $\mathrm{A}_{\mathrm{zz}}$ & $\mathrm{A}_{\mathrm{xx}}$ & $\mathrm{A}_{\mathrm{yy}}$ & \\
\hline DCBMZ & 2.424 & 2.121 & 2.066 & 14.18 & 3.62 & 2.1 & \\
\hline $\begin{array}{l}\text { Powder } \\
\text { DCBMZ }\end{array}$ & 2.391 & 2.080 & 2.080 & 12.52 & - & - & $\begin{array}{c}\text { Present } \\
\text { case }\end{array}$ \\
\hline $\mathrm{DBMZ}^{\mathrm{a}}$ & 2.424 & 2.121 & 2.105 & 14.18 & 3.62 & 2.10 & 26 \\
\hline DAMZ $^{\mathrm{b}}$ & 2.442 & 2.087 & 2.077 & 14.74 & 2.88 & 1.83 & 27 \\
\hline LGS $^{c}$ & 2.372 & 2.188 & 2.032 & 8.00 & 6.50 & 5.0 & 29 \\
\hline $\mathrm{HZBMZ}^{\mathrm{d}}$ & 2.369 & 2.088 & 2.088 & 11.47 & 2.63 & 2.63 & 32 \\
\hline
\end{tabular}

${ }^{a}$ DBMZ: Diaqua(2,2-bipyridine) malonatozinc(II). ${ }^{b}$ DAMZ: Diaqua malonatozinc(II). ${ }^{c}$ LGS: Lithium glycein sulphate. ${ }^{\mathrm{d}} \mathrm{HZMBZ}$

Hexaquabismalatodiauamalonatezinc(II).

value of $\mathrm{R}$ in the present case is 0.154 which is less than unity, therefore the ground state of $\mathrm{Cu}(\mathrm{II})$ in DCBMZ lattice is $\mathrm{d}_{x^{2}-y^{2}}$. The close look values of direction cosines of principal $g$ and $\mathrm{A}$ are very close to each other, further was confirmed by having the maxima and minima at the same angle in the isofrequency plots of all the three planes. Generally these values are compared with the direction cosines obtained from crystallographic data $(\mathrm{Zn}-\mathrm{O})$ to get information about the location of the dopant. The direction cosines of the ( $\mathrm{Zn}-\mathrm{O})$ bond have been calculated from the crystal data of the host lattice ${ }^{18}$ and values are given in Table-2. The crystal structure of DCBMZ is shown in Fig. 1. While comparing the direction cosines of metal ligand bond and direction cosines obtained by EPRNMR program of $g$ and A matrix, none of them matches. From this surveillance, it is concluded that the paramagnetic $\mathrm{Cu}$ (II) impurity might have entered the lattice interstitially and not substitutionally.

The location of the paramagnetic impurity site observed for $\mathrm{Cu}(\mathrm{II})$ doped in DCBMZ is interstitial. We have analyzed crystal structure of DCBMZ (Fig. 1). DCBMZ posses one molecule per unit cell $(\mathrm{Z}=1)$ under the space group $\mathrm{PI}^{-}$. Zinc atom is coordinated with six oxygens, four from two different malonate groups build the equatorial plane and two oxygen 
from two symmetrical water molecule made of elongated octahedral geometry. Cesium atom is eight coordinated with square antiprism environments. For the present case dopant ion is copper and preferred to replace host zinc ion because both have comparable ionic radii and same oxidation state. But not favoured to replace cesium atom because it is univalent ion. The $3 d^{9}$ ion with $\mathrm{s}=1 / 2$ and $\mathrm{I}=3 / 2$ exhibits four line hyperfine pattern from a $\mathrm{Cu}(\mathrm{II})$ doped DCBMZ single crystal. $\mathrm{Cu}$ (II) ion has been planned to entered in the host lattice interstitially because both metal atoms ( $\mathrm{Zn}$ and $\mathrm{Cs}$ ) are strongly coordinate malonate bridge and also breaking of metal ligand bonds ( $\mathrm{Zn}-\mathrm{O}$ and Cs-O) also very difficult. Suppose zinc atom coordinated with six water molecule, it is very easy to replace by dopant copper ion but present system is very complicate due to carboxylate group.

Polycrystalline EPR spectrum: The single crystal data is normally cross checked using the powder sample. The EPR spectrum of the powder sample is recorded at room temperature and is shown in Fig. 5. The spin Hamiltonian parameters have been calculated from powder spectrum and the values are shown below,

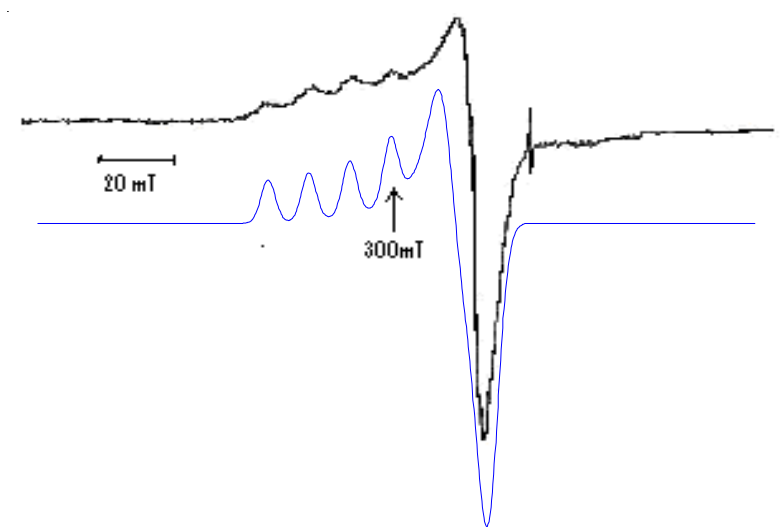

Fig. 5. Powder EPR spectrum of $\mathrm{Cu}(\mathrm{II})$ doped DCBMZ recorded at RT (top) whereas bottom one simulated using simfonia program. Frequency $=9.08161 \mathrm{GHz}$

$\mathrm{g}_{\|}=2.391, \mathrm{~g}_{\perp}=2.080 . \mathrm{A}_{\|}=12.52 \mathrm{mT}$ and $\mathrm{A}_{\perp}$ was not resolved

The $\mathrm{g}$ and $\mathrm{A}$ values for $\mathrm{Cu}(\mathrm{II})$ doped $\mathrm{DCBMZ}$ powder sample are close to those obtained for single crystal (Table-1). The parallel $\mathrm{g}$ value is greater than perpendicular value indicates that the ground state is $d_{x^{2}-y^{2}}$. The RT spectrum is also simulated powder spectrum and is given along with experimental one in Fig. 5, where the agreement is excellent.

Calculation of admixture and molecular orbital parameters: The spin Hamiltonian parameters indicate $\mathrm{d}_{\mathrm{x}^{2}-\mathrm{y}^{2}}$ ground state of the $\mathrm{Cu}$ (II) ions. The non-axial symmetry of the $g$ and A tensor suggest a rhombic crystal field symmetry. The wave function for the ground state Kramers' is

$$
\begin{gathered}
\Psi=\mathrm{a} \phi_{1} \alpha+\mathrm{b} \phi_{3} \alpha+\mathrm{ic} \phi_{2} \alpha-\mathrm{id} \phi_{4} \beta-\mathrm{e} \phi_{5} \beta \\
\Psi^{*}=\mathrm{i}\left(\mathrm{a} \phi_{1} \beta+\mathrm{b} \phi_{3}-\mathrm{ic} \phi_{2}-\mathrm{id} \phi_{4}+\mathrm{e} \phi_{5} \alpha\right)
\end{gathered}
$$

where $\phi_{1}=\mathrm{dz}^{2}(\mathrm{~A}), \phi_{2}=\mathrm{d}_{\mathrm{xy}}\left(\mathrm{B}_{1}\right), \phi_{3}=\mathrm{dx}^{2}-\mathrm{y}^{2} \phi_{4}=\mathrm{d}_{\mathrm{yz}}(\mathrm{B} 3), \phi_{5}=$ $\mathrm{d}_{\mathrm{xz}}(\mathrm{B} 2)^{21}$. Equation represents that if $\mathrm{a}=1$, the system has the $\mathrm{d}_{\mathrm{z}^{2}}$ ground state and lowest $A_{\|}$value and if $b=1$, the system is in $d_{x^{2}-y^{2}}$ ground state and has the maximum hyperfine value. a, $\mathrm{b}, \mathrm{c}, \mathrm{d}$ and e are the coefficients of $\phi_{1}, \phi_{2}, \phi_{3}, \phi_{4}$ and $\phi_{5}$, respectively. These coefficients do not reflect the covalency of the metal ligand bonds but rather restrict themselves to give an indication of the mixing among the $d$-orbitals brought about by metal spin-orbit coupling. Here, the cross terms involving ligand spin-orbit coupling are neglected. The expression for the g-vales (in terms of admixture coefficients) are given ss $^{22}$

$$
\begin{aligned}
& g_{z}=2-4 d^{2}-4 e^{2}+8 b c+4 d e \\
& g_{x}=2-4 c^{2}-4 e^{2}+4 \sqrt{3 a d}-4 c e+4 b d \\
& g_{y}=2-4 c^{2}-4 d^{2}+4 \sqrt{3 a e}-4 b e+4 c d
\end{aligned}
$$

Using the normalization condition and assuming $\mathrm{e}=-\mathrm{d}$, values of $a, b, c$ and $d$ are obtained by iterative procedure. The coefficients, which gives the best fit to the observed $g$ values are listed in Table- 4 and compared with those reported for a few other systems. A comparison of these results reveals that there is considerable admixture of $d$-orbitals in the present compounds. The dipolar term P and Fermi contact parameter $\kappa$ are evaluated ${ }^{22,23}$ from the following expressions.

TABLE-4

$d$-ORBITAL COEFFICIENTS OF THE GROUND STATE WAVE

FUNCTION FOR Cu(II) IN DCBMZ AND FEW RELATED Cu(II) SYSTEMS IN LOW SYMMETRY ENVIRONMENTS. ABBREVIATION OF $b, c, d$ ARE ALREADY GIVEN IN TABLE-3

\begin{tabular}{lcccccc}
\hline Compound & $\mathrm{a}$ & $\mathrm{b}$ & $\mathrm{c}$ & $\mathrm{d}$ & $\mathrm{e}$ & Ref. \\
\hline DCBMZ & 0.144 & 0.988 & 0.052 & 0.019 & -0.019 & Present \\
DAMZ $^{\mathrm{b}}$ & 0.144 & 0.988 & 0.058 & 0.019 & -0.019 & 25 \\
LGS $^{\mathrm{C}}$ & 0.144 & 0.988 & 0.041 & 0.019 & -0.019 & 28 \\
HZBMZ $^{\mathrm{d}}$ & 0.250 & 0.966 & 0.052 & 0.021 & -0.021 & 27 \\
\hline
\end{tabular}

$$
\begin{gathered}
\mathrm{A}_{\|}=\mathrm{P}\left[-\left(\frac{4 \alpha^{2}}{7}\right)-\mathrm{k}+\left(\mathrm{g}_{\|}-\mathrm{g}_{\mathrm{e}}\right)+\frac{3}{7}\left(\mathrm{~g}_{\perp}-\mathrm{g}_{\mathrm{e}}\right)\right] \\
\mathrm{A}_{\perp}=\mathrm{P}\left[\left(\frac{2 \alpha^{2}}{7}\right)-\mathrm{k}+\frac{11}{14}\left(\mathrm{~g}_{\perp}-\mathrm{g}_{\mathrm{e}}\right)\right]
\end{gathered}
$$

Here, $\mathrm{P}=2 \gamma \mathrm{Cu} \beta \beta \mathrm{n}<\mathrm{r}^{-3}>, \gamma \mathrm{Cu}$ is the gyromagnetic ratio of copper, $\beta$ is the Bohr magneton and bn is the nuclear magneton and $\beta_{\mathrm{n}}$ is the dimension less hyperfine interaction constant. The average of $A_{x}$ and $A_{y}$ is taken as $A_{\perp}$. These parameters are calculated for $\mathrm{Cu}$ (II)/DCBMZ and tabulated in Table-5 with other related systems for comparison.

\begin{tabular}{lcccc}
\multicolumn{5}{c}{ TABLE-5 } \\
\multicolumn{5}{c}{$\begin{array}{c}\text { MOLECULAR ORBITAL COEFFICIENT } \\
\text { FOR SOME Cu(II) }) \text { SYSTEMS }\end{array}$} \\
\hline Compound & $\alpha^{2}$ & $\mathrm{~K}$ & $\mathrm{P}\left(10^{-4} \mathrm{~cm}^{-1}\right)$ & Reference \\
\hline DBMZ & 0.753 & 0.2710 & 351 & Present \\
DAMZ & 0.790 & 0.284 & 240 & 26 \\
ZPPH & 0.678 & 0.281 & 165 & 29 \\
DABMZ & 0.869 & 0.476 & 243 & 25 \\
HZBMZ & 0.780 & 0.350 & 303 & 31 \\
\hline
\end{tabular}

According to Kivelson and Neiman, $\mathrm{k}=\alpha^{2} \mathrm{k}_{0}$, where $\mathrm{k}_{0}$ is the free ion parameter which estimated by Abragam and Pryce ${ }^{24}$ to be 0.36 . Using the above expression, the values of $\mathrm{P}$ and $\mathrm{k}$ can be calculated. The $\mathrm{P}$ value for free ion is $360 \times 10^{-4} \mathrm{~cm}^{-1}$. The values of $\mathrm{P}$ and $\mathrm{k}$ obtained for our present system $-312 \times$ $10^{-4} \mathrm{~cm}^{-1}$ and 0.35 , respectively. The ratio of $\mathrm{P}$ values obtained for complex to that of the free ion value is around $87 \%$, indicating the localization of $d$-electron. The percentage of 
unpaired spin density on copper ion is $13 \%$ and the remaining density is being distributed onto the ligands. The molecular orbital coefficient $\alpha^{2}$ which gives a measure of covalent nature of $\sigma$-bonding is given $\mathrm{as}^{25}$.

$$
\alpha^{2}=\frac{\mathrm{A}_{\|}}{0.036}+\left(\mathrm{g}_{\|}-2.0023\right)+\frac{3}{7}\left(\mathrm{~g}_{\perp}-2.0023\right)+0.04
$$

$\alpha^{\prime}$ can be evaluated from the normalization condition on the ground state orbital as

$$
\alpha^{\prime}=\left(1-\alpha^{2}\right)^{1 / 2}+\sigma S
$$

where $S$ is the overlap integral between the $d_{x^{2}-y^{2}}$ orbital and normalized ligand orbital. The value of $\mathrm{S}$ is given as 0.076 for copper complex. This complex found to be partially covalent nature. For $\mathrm{Cu} / \mathrm{DCBMZ}$ the bonding parameter

$$
\alpha^{2}=0.78 \quad \alpha=0.88 \quad \alpha^{\prime}=0.5276
$$

The value of $\alpha^{2}$ is unity if the bond between metal and the ligands is ionic and 0.5 if it is covalent. The present value 0.780 indicates partially covalent nature for the metal ligand bond. Hence, admixture of $\mathrm{d}_{\mathrm{x}^{2}-\mathrm{y}^{2}}$ and $\mathrm{d}_{\mathrm{z}^{2}}$ orbital and covalency contribute to the low magnitude of the $\mathrm{Cu}$ (II) hyperfine constant $\mathrm{t}^{26-32}$

\section{Conclusion}

Single crystal rotations in the three planes indicate that only one site noticed for copper impurity present in DCBMZ lattice. The spin Hamiltonian parameters for the $\mathrm{Cu}$ (II) doped DCBMZ have been achieved from single crystal rotation in the three orthogonal planes. The principal $g$ and A parameters are evaluated from EPR spectra using EPR NMR program. The spin Hamiltonian parameters have been calculated and direction cosines values confirm that the impurity has entered the lattice in an interstitial position. The isofrequency plots and the powder EPR have also been simulated, which is used evaluated spin Hamiltonian parameters. Fermi contact term $(\kappa)$ and dipolar interaction parameter $(\mathrm{P})$ have also been evaluated. The ground state wave function for copper in DCBMZ is constructed. From the optical data, we have calculated tetragonal parameters (Dt). Zn-O, -COO- and -OH bonds are confirmed by FTIR. Powder XRD confirms the structure of the lattice DCBMZ.

\section{ACKNOWLEDGEMENTS}

The authors thank the University Grand Commission [33]316/2007(2007)] for financial assistance. P. Geetha dedicates this paper to (Late) Dr. P. Sambasiva Rao for his valuable guidance in her research work.

\section{REFERENCES}

1. B. Hue, M.L. Tong and X.M. Chen, Coord. Chem. Rev., 249, 545 (2005).

2. C. Ruiz-Perez, Y. Rodriguez-Martin, M. Hernandez-Molina, F.S. Delgado, J. Pasan, J. Sanchiz, F. Lloret and M. Julve, Polyhedron, 22, 2111 (2003).

3. J. Pasan, F.S. Delgado, Y. Rodriguez-Martin, M. Hernandez-Molina, C. Ruiz- Perez, J. Sanchiz, F. Lloret and M. Julve, Polyhedron, 22, 2143 (2003).

4. C. Oldham, In eds.: G. Wilkinson, R.D. Gillard and J.A. McCleverty, Comprehensive Coordination Chemistry, Pergamon Press, Oxford, Vol. 2 (1987).

5. R. Hoskins and R. Robson, J. Am. Chem. Soc., 112, 1546 (1990).

6. G.B. Gardner, D. Venkataraman, J.S. Moore and S. Moore, Nature, 374, 792 (1995).

7. D. Chattopadhya, S.K. Chttopadhyay, P.R. Lowe, C.H. Schwalbe, S.K. Mazumder, A. Rana and S. Ghosh, J. Chem. Soc. Daltan Trans., 913 (1993).

8. S. Kitagawa, S. Noro and T. Nakamura, Chem. Commun., 701 (2006).

9. D. Reinen, M. Atanasov, P. Kohler and D. Babel, Coord. Chem. Rev., 254, 2703 (2010).

10. B.J. Hathaway and G. Wilkinson, Comprehensive Coordination Chemistry, vol. 5, Pergamon Press, New York (1987).

11. B.J. Hathaway and D.E. Billing, Coord. Chem., 5, 143 (1970).

12. N. Wei, N.N. Murthy and K.D. Karlin, Inorg. Chem., 33, 6093 (1994).

13. M. Velayutham, B. Varghese and S. Subramanian, Inorg. Chem., 37, 5983 (1998).

14. G.A. Mclachlan, G.A. Fallon, R.L. Martin and L. Spiccia, Inorg. Chem., 34, 254 (1995).

15. P. Comba, T.W. Hambley, M.A. Hitchman and H. Stratemeier, Inorg. Chem., 34, 390 (1995).

16. J.G. Lozano, J.S. Carrio, E. Escriva, J.V. Foldado, C. Molla and L. Lezama, Polyhedron, 16, 939 (1997).

17. D. Reinen and C. Friebel, Inorg. Chem., 23, 791 (1984).

18. F.S. Delgado, C.R. Perez, J. Sanchiz, F. Llret and M. Julve, Cryst. Eng. Commun., 8, 507 (2006).

19. C.J. Ballhausen and H.B. Gray, Inorg. Chem., 1, 111 (1962).

20. F. Clark, R.S. Dickson, D.B. Fulton, J. Isoya, A. Lent, D.G. McGavin, M.J. Mombourquette, R.H.D. Nuttal, P.S. Rao, H. Rinnerberg, W.C. Tennat and J.A. Weil, EPR -NMR Program, University of Saskatchewan, Saskatoon, Canada (1996).

21. J.D. Swalen, B. Johnson and H.M. Gladney, J. Chem. Phys., 52, 4078 (1970).

22. A.H. Maki and B.R. McGarvey, J. Chem. Phys., 29, 31 (1958).

23. D. Kivelson and R.J. Neiman, J. Chem. Phys., 35, 149 (1961).

24. A. Abragam and M.H.L. Pryce, Proc. Royal Soc. Ser. A, 205, 135 (1950).

25. J.J. Prochaska, W.F. Schwindger, M. Schwartz, M.H. Burk, E. Bernarducci, R.A. Lalancettee, J.A. Potenga and H.J. Schugar, J. Am. Chem. Soc., 103, 3446 (1981).

26. K. Parthipan and P. Sambasiva Rao, J. Mol. Struct., 977, 130 (2010).

27. S. Mithira, B. Natarajan, S. Deepa, R.V.S.S.N. Ravikumar and P.S. Rao, J. Mol. Struct., 839, 2 (2007).

28. I. Sougandi, R. Venkatesan and P. Sambasiva Rao, Spectrochim. Acta A, 60, 2653 (2004).

29. P.N. Selva Kumar, B. Natarajan, P. Sambasiva Rao and P. Subramanian, Cryst. Res. Technol., 35, 3337 (2008).

30. K.C. Naidu, C. Shiyamala, S. Mithira, B. Natarajan and P.S. Rao, Radiat. Eff. Defects Solids, 160, 225 (2006).

31. H. Ramesh, K. Parthipan and P.S. Rao, Appl. Magn. Reson, 40, 513 (2011).

32. S. Boobalan and P. Sambasiva Rao, J. Phys. Chem. Solids, 71, 1527 (2010).

33. P. Geetha, K. Parthipan and P.S. Rao, Appl. Magn. Reson, 42, 187 (2012). 